\title{
Role of nitric oxide synthases in elastase-induced emphysema
}

\author{
Laurent Boyer ${ }^{1,2,3}$, Laurent Plantier ${ }^{4,5}$, Maylis Dagouassat ${ }^{1}$, Sophie Lanone ${ }^{1}$, Delphine Goven ${ }^{4}$, Philippe Caramelle , \\ François Berrehar ${ }^{6}$, Stephane Kerbrat ${ }^{1}$, Anh-Tuan Dinh-Xuan ${ }^{7}$, Bruno Crestani ${ }^{4,5,8}$, Sabine Le Gouvello ${ }^{1,2,6}$ and \\ Jorge Boczkowski ${ }^{1,2,9}$
}

Nitric oxide (NO) in combination with superoxide produces peroxynitrites and induces protein nitration, which participates in a number of chronic degenerative diseases. NO is produced at high levels in the human emphysematous lung, but its role in this disease is unknown. The aim of this study was to determine whether the NO synthases contribute to the development of elastase-induced emphysema in mice. nNOS, iNOS, and eNOS were quantified and immunolocalized in the lung after a tracheal instillation of elastase in mice. To determine whether eNOS or iNOS had a role in the development of emphysema, mice bearing a germline deletion of the eNOS and iNOS genes and mice treated with a pharmacological iNOS inhibitor were exposed to elastase. Protein nitration was determined by immunofluorescence, protein oxidation was determined by ELISA. Inflammation and MMP activity were quantified by cell counts, RT-PCR and zymography in bronchoalveolar lavage fluid. Cell proliferation was determined by Ki67 immunostaining. Emphysema was quantified morphometrically. iNOS and eNOS were diffusely upregulated in the lung of elastase-treated mice and a 12-fold increase in the number of 3-nitrotyrosine-expressing cells was observed. Over $80 \%$ of these cells were alveolar type 2 cells. In elastaseinstilled mice, iNOS inactivation reduced protein nitration and increased protein oxidation but had no effect on inflammation, MMP activity, cell proliferation or the subsequent development of emphysema. eNOS inactivation had no effect. In conclusion, in the elastase-injured lung, iNOS mediates protein nitration in alveolar type 2 cells and alleviates oxidative injury. Neither eNOS nor iNOS are required for the development of elastase-induced emphysema.

Laboratory Investigation (2011) 91, 353-362; doi:10.1038/labinvest.2010.169; published online 18 October 2010

KEYWORDS: inflammation; nitrosative stress; oxidative stress; pulmonary emphysema

Free radical toxicity is one of the main contributors to the development of pulmonary emphysema, a frequent chronic degenerative disease of the lung characterized by reduced maximal expiratory flow, increased lung volume, and alveolar wall destruction. This phenomenon has been well demonstrated with regard to the role of reactive oxygen species, and in particular the superoxide anion ${ }^{1-3}$ pertaining to the concept of oxidative stress. By analogy, a similar role has been suspected to be played by nitrogen reactive species, and in particular by nitric oxide $(\mathrm{NO})$, pertaining to the concept of nitrosative stress.

$\mathrm{NO}$ is the principal reactive nitrogen species encountered in vivo. It is produced from L-arginine by the neuronal, endothelial, and inducible isoforms of the NO synthase (nNOS, iNOS, and eNOS). In addition to its multiple physiological properties, $\mathrm{NO}$ at high concentrations exerts toxicity through its combination with superoxide anion to form peroxynitrite $\left(\mathrm{ONOO}^{\bullet-}\right)$. $\mathrm{ONOO}^{\bullet-}$ in turn induces nitration of lipids, nucleic acids, and proteins, distorting their structure and altering their function. Peroxynitritemediated cytotoxycity has a key role in the pathogenesis of a number of chronic degenerative diseases of the brain, heart, and liver. ${ }^{4}$

Several clues suggest a role for NO and the NOS in the course of pulmonary emphysema. Increased levels of alveolar $\mathrm{NO}$ are measured in patients with severe chronic obstructive

\footnotetext{
${ }^{1}$ INSERM, Unité U955, Créteil, France; ${ }^{2}$ Université Paris Est, Faculté de Médecine, UMR U955, Créteil, France; ${ }^{3}$ AP-HP, Groupe Henri-Mondor Albert-Chenevier, Service de Physiologie Explorations Fonctionnelles, Créteil, France; ${ }^{4}$ INSERM, Unité U700, Paris, France; ${ }^{5}$ Université Paris 7, Faculté de Médecine Xavier Bichat, UMR U700, Paris, France; ${ }^{6}$ AP-HP, Groupe Henri-Mondor Albert-Chenevier, Service d'Immunologie Biologique, Créteil, France; ${ }^{7}$ AP-HP, Groupe Cochin Saint Vincent de Paul, Service de Physiologie Explorations Fonctionnelles, Université Paris Descartes, Paris, France; ${ }^{8}$ AP-HP, Hôpital Bichat, Service de Pneumologie, Paris, France and ${ }^{9} \mathrm{Centre} \mathrm{Hospitalier}$ Intercommunal de Créteil, Service de Pneumologie, Créteil, France

Correspondence: Dr L Boyer, MD, INSERM, Unité U955, Faculté de Medicine, 8 rue du Général Sarrail, Créteil 94000, France.

E-mail: laurent.boyer@hmn.aphp.fr

Received 4 November 2009; revised 13 August 2010; accepted 30 August 2010
} 
pulmonary disease, ${ }^{5}$ whereas protein nitration is detected in the airway of such patients. ${ }^{6}$ In line with these results, the expression of iNOS is exaggerated and is correlated with the extent of protein nitration in the alveolar walls of patients with pulmonary emphysema. ${ }^{7}$ However, although markers of nitrosative stress are present in the lung of patients with emphysema, leading some authors to suggest a role for this phenomenon in the process of disease $e^{6,8-10}$; the relationship between nitrosative stress and the development of emphysema is unknown.

To clarify this point, we sought to determine whether NOS isoforms had a role in an animal model of emphysema. First, we determined the level of nNOS, iNOS, and eNOS expression as well as the extent of protein nitration in the lung of mice after a tracheal instillation of elastase, a well-documented model of experimental emphysema. Second, we determined whether inactivation of iNOS or eNOS influenced markers of nitrosative and oxidative stress, inflammation, protease activity and the development of emphysema in the lung following elastase instillation.

\section{MATERIALS AND METHODS Animal Model}

Male 8-week-old mice of C57BL/6 background were anesthetized and received a tracheal instillation of saline or $5 \mathrm{U}$ of porcine pancreatic elastase (EC134, Elastin Products, Owensville, MO, USA) as previously described. ${ }^{11}$ In some experiments, $\mathrm{iNOS}^{-1-}$ and $\mathrm{eNOS}^{-1-}$ animals were used, with wild-type C57BL/6 mice as controls (Jackson Laboratory, Bar Harbor, ME, USA). In other experiments, wild-type mice (Janvier, Le Genest Saint-Isle, France) were treated subcutaneously with two injections of $10 \mathrm{mg} / \mathrm{kg}(20 \mathrm{mg} / \mathrm{kg} /$ day) $\mathrm{N}$-3-aminomethyl-benzyl-acetamidine-dihydrochloride (1400W, Cayman Chemical, Ann Arbor, MI, USA), a specific iNOS inhibitor, ${ }^{12}$ from the day before tracheal instillation to the day they were killed, whereas control mice received saline injections. Another experiment was conducted with daily $1400 \mathrm{~W}$ at $1 \mathrm{mg} / \mathrm{kg} / \mathrm{day}$. In other experiments, Balb/c mice (Janvier) were used. Studies were conducted in compliance with INSERM guidelines regarding the fair treatment of animals, under a license from the French administration to conduct animal research as described in the protocol.

\section{Determination of nNOS, iNOS, and eNOS mRNA and Protein Levels in Lung Homogenate}

Total mRNA was prepared from the crushed lung of the different mice, using RNeasy Protect Mini Kit (Qiagen, ZA Courtaboeuf, France) following the manufacturer's protocol. First-strand cDNA was synthesized in RT samples, each containing: $2.5 \mu \mathrm{g}$ total RNA isolated from cells, $8 \mathrm{U} / \mu \mathrm{l}$ M-MLV reverse transcriptase (Gibco-BRL, Life Technologies, Cergy-Pontoise, France), $4 \mu \mathrm{M}$ Oligo-(dT) 12-18 (Invitrogen, Cergy-Pontoise, France), and $0.8 \mathrm{mM}$ mixed dNTP (GE Healthcare, Saclay, France). Quantitative PCR was performed in a $7900 \mathrm{HT}$ Real-Time PCR system (Applied
Biosystems, ZA Courtaboeuf, France), using Fast SYBR Master Mix from Applied Biosystems. The sequences of primers are indicated in Supplementary Table 1. Normalization was achieved by quantification of the expression of either CXXC1 or ribosomal protein 13 mRNA (RPL13) as described previously, ${ }^{11}$ chosen as control housekeeping genes (HKG) among four HKG tested because of their stable expression in the different conditions of the experiment (KO iNOS and $1400 \mathrm{~W}$-treated mice with or without tracheal instillation of elastase), and/or their adequate expression level as compared with the considered target gene. All PCR conditions were adjusted in order to obtain equivalent optimal amplification efficiency between the different assays. Mice's lung mRNA expression were quantified by relative quantification ( $\Delta \Delta \mathrm{CT}$ method) according to Pfaffl et al ${ }^{13}$ using an equal mix of each cDNA sample from the different mice's lung, as calibrator sample. All PCR experiments were done in triplicate.

iNOS, nNOS, and eNOS lung protein levels were determined at day 7 after instillation by western blot analysis using $100 \mu \mathrm{g}$ protein with antibodies binding iNOS (VPA5382 Abcys, Paris, France), eNOS and nNOS (610296 and 610309, BD Transduction Laboratories, San Jose, CA, USA) diluted 1/1000. $\beta$-Actin (A2228, Sigma, St Louis, MO, USA) was used as an internal control.

\section{Localization of iNOS and eNOS Expression in the Lung}

The expression of iNOS and eNOS was localized by confocal microscopy on $5 \mu \mathrm{m}$-thick frozen lung sections permeabilized with $0.1 \%$ Triton $\times 100$ (Sigma) using rabbit anti-iNOS (VPA5382, Abcys, diluted $1 / 500$ for $1 \mathrm{~h}$ at $37^{\circ} \mathrm{C}$ ) and antieNOS (610298, BD Transduction Laboratories, diluted 1/25 for $1 \mathrm{~h}$ at $37^{\circ} \mathrm{C}$ ) antibodies, with normal rabbit serum (Vector, Peterborough, UK) as a control, revealed with a goat Alexa fluor 546-conjugated anti-rabbit secondary antibody (A11010, Molecular Probes, Eugene, OR, USA). Alveolar type 2 cells were localized with a rabbit anti-proSFTPC antibody (AB3786, Chemicon, Temecula, CA, USA, diluted 1/250 for $1 \mathrm{~h}$ at $37^{\circ} \mathrm{C}$ ) and revealed with the Zenon Rabbit IgG Labeling Kit Alexa fluor 488 (Z-25302, Molecular Probes). Macrophages were detected with a rat anti-MAC3 antibody (550292, BD Pharmingen, diluted $1 / 750$ for $1 \mathrm{~h}$ at room temperature) and revealed with a goat Alexa fluor 488-conjugated anti-rat secondary antibody (A-11006, Molecular Probes). Nuclei were stained with TO-PRO-3 (Molecular Probes). Slides were examined with an LSM-510-META confocal laser scanning microscope (Zeiss, Oberkochen, Germany).

\section{Quantification and Localization of Nitrated Proteins in the Lung}

The accumulation in the lung of 3-nitrotyrosine, a marker of protein nitration, was determined by immunofluorescence microscopy on frozen lung sections using a rabbit anti3-nitrotyrosine polyclonal antibody (05-233, Upstate 
biotechnology, Temecula, CA, USA, diluted to $0.5 \mu \mathrm{g} / \mathrm{ml}$ for $1 \mathrm{~h}$ at $37^{\circ} \mathrm{C}$ ) and revealed with a goat Alexa fluor 546-conjugated anti-rabbit secondary antibody (A11010, Molecular Probes). The accumulation of 3-nitrotyrosine in the lung was quantified by counting the number of 3-nitrotyrosineexpressing cells in 10 microscopic fields per slide at $\times 20$ magnification using a Zeiss Axiophot fluorescence microscope.

Double immunostaining confocal microscopy experiments were performed as described above to determine the type of 3-nitrotyrosine-expressing cells. The number of doublestained cells was reported to the number of proSFTPCpositive or MAC3-positive cells and was expressed as a percentage.

Quantification of Oxidative Stress Markers in the Lung Oxidized protein levels were determined in total lung homogenate by ELISA using the OxiSelect Protein Carbonyl ELISA kit (STA-310, Cell Biolabs, San Diego, CA, USA). Heme Oxygenase 1 (HO1) mRNA was quantified in lung homogenate by RT-PCR as described above. The sequences of primers are indicated in Supplementary Table 1.

\section{Quantification of Pulmonary Inflammation and Protease Activity}

The intensity of the pulmonary inflammatory reaction was assessed in bronchoalveolar lavage fluid (BALF). Lungs were lavaged with $2 \mathrm{ml}$ saline, and cells were differentially counted with the Diff-Quick stain (Baxter-Dade AG, Dudingen, Germany). The concentration in BALF of the chemoattractant chemokine CCL2 was determined by ELISA (R\&D Systems, Lille, France). Gelatin zymography was performed on BALF as described previously. ${ }^{11}$ To explore the effect of iNOS inactivation on the mechanisms driving lung inflammation in this model, we quantified the expression of CCL2, CXCL2, tumor necrosis factor- $\alpha(\mathrm{TNF} \alpha)$, and interleukin-6 (IL6) mRNAs normalized by CXXC1 mRNA, as described above. The sequences of primers are indicated in Supplementary Table 1. CCL2 protein levels were determined in BALF by ELISA (R\&D Systems).

\section{Determination of Ki67 Expression in the Lung}

The accumulation in the lung of Ki67, a cell cycle related nuclear protein expressed by proliferating cells, was determined by immunohistochemistry on frozen lung sections using a rabbit ki67 polyclonal antibody (Ab66155, Abcam, MA, USA, diluted $1 / 300$, overnight at $4{ }^{\circ} \mathrm{C}$ ) and revealed with the Vectastain ABC-peroxydase kit system (PK 4001, Vector Laboratories, CA, USA). The number of Ki67-positive cells was counted in 10 microscopic fields at $\times 20$ magnification and expressed as a percentage.

\section{Morphological Analysis}

The lungs were fixed with $2.5 \%$ glutaraldehyde at a transpleural pressure of $25 \mathrm{cmH}_{2} \mathrm{O}$ for $3 \mathrm{~h}$ and held in $4 \%$ paraformaldehyde (Sigma). Great-axis sagittal sections $(5 \mu \mathrm{m})$ of the left lung were cut in a systematic manner and were stained with hematoxylin and eosin. Five blackand-white digital photomicrographs were acquired from the cranial, medial, and caudal regions of each slide at $\times 100$ magnification, excluding areas where large bronchi or vessels predominated, resulting in a total of 15 images per lung. Emphysema was then quantified by measurement of the mean chord length of alveoli with Analysis software (Soft Imaging System, Münster, Germany) at a 5- $\mu \mathrm{m}$ interval. This automated analysis was made vertically and horizontally on each photomicrograph. The mean chord length of alveoli was obtained by averaging those measurements. ${ }^{11}$

\section{Statistical Analysis}

Data were expressed as means \pm s.e. and were analyzed with GraphPad Prism 4.0 (La Jolla, CA, USA). Comparisons between multiple groups were performed with Kruskall-Wallis' non-parametric analysis of variance test followed when a difference was detected by two-by-two comparisons with Mann-Whitney's $U$ test. $P$-values $<0.05$ were considered significant.

\section{RESULTS \\ Elastase Induced the Pulmonary Expression of iNOS and eNOS}

Elastase instillation induced a marked increase in lung iNOS mRNA (Figure 1a). This increase was present from day 1 post-instillation, reached a maximum on day 7 , and persisted to day 20. This increase in iNOS mRNA in elastase-treated mice translated into a $433 \%$ increase in the pulmonary content of iNOS protein as assessed by western blotting in lung homogenate at day $7(P=0.002)$.

In comparison to control mice, eNOS mRNA was significantly increased in the lungs of elastase-treated mice from day 1 to day 20, peaking at day 1 and decreasing thereafter (Figure 1b). Accordingly, a 380\% increase in eNOS protein was observed in the lung of those animals at day 7 $(P=0.016)$.

Lung nNOS mRNA was decreased at days 1 and 7 following elastase instillation (Figure 1c). nNOS protein levels in lung homogenate of those mice were similar to those observed in control animals.

Confocal microscopy analysis was performed to determine which cell types were responsible for the increased expression of eNOS and iNOS in the elastase-injured lung. iNOS and eNOS were expressed at low levels in the lungs of control mice. In elastase-induced mice, iNOS was diffusely expressed in alveolar walls. Colocalization experiments showed that iNOS was expressed by $80.5 \pm 7.8 \%$ of macrophages, identified by MAC3 staining, as well as $42.3 \pm 8.6 \%$ of alveolar type 2 cells, identified by proSFTPC staining (Figure 2). Likewise, eNOS expression was diffuse and involved both macrophages and alveolar type 2 cells (respectively, $81.5 \pm 0.7 \%$ and $14.7 \pm 4.8 \%$ of these cells expressed eNOS). 

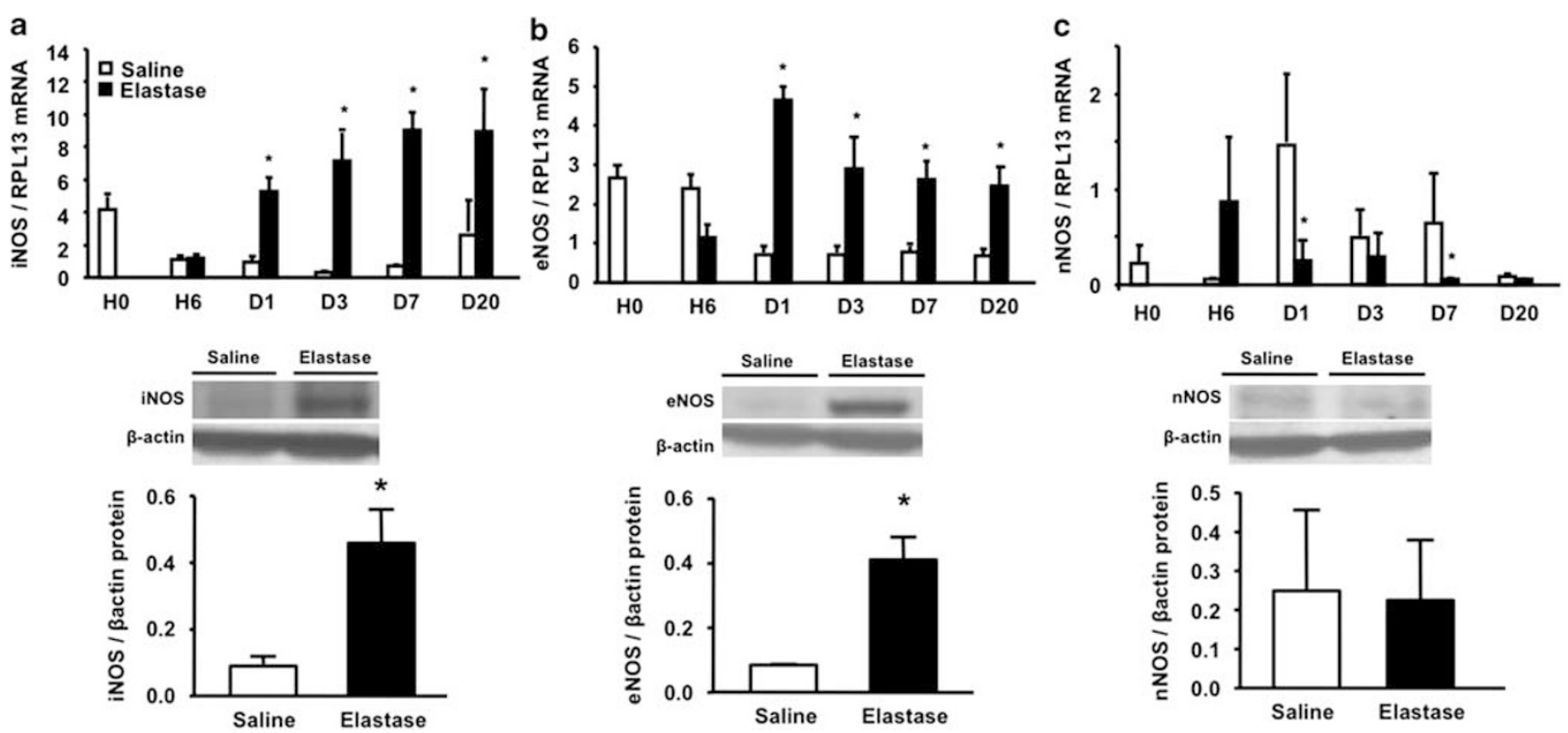

Figure 1 Pulmonary expression of iNOS, eNOS, and nNOS at day 7 after elastase instillation. Expression of iNOS (a), eNOS (b), and nNOS (c). (Upper panels) iNOS, eNOS, and nNOS mRNA in lung homogenate before (H0), $6 \mathrm{~h}(\mathrm{H} 6)$, and 1, 3, 7, and 20 days (D1, D3, D7, and D20) after a tracheal instillation of saline solution (open bars) or elastase (filled bars), reported to RPL13 mRNA, $n=5$. (Lower panels) iNOS, eNOS, and nNOS protein reported to $\beta$-actin protein in lung homogenate at day 7 after elastase instillation. Representative western blot experiment and densitometric measurements, $n=5$. Mean \pm s.e. ${ }^{*} P<0.05$ vs saline.

\section{Elastase Induced the Accumulation of Nitrated Proteins in Alveolar Type 2 Cells}

To determine whether pulmonary overexpression of NO synthases was accompanied by nitrosative stress in this model, nitration of lung proteins was detected by immunofluorescence at day 7 after elastase instillation. Quantitatively, elastase induced a $1100 \%$ increase in the number of 3nitrotyrosine-positive cells in the lung $(P=0.029$, Figure 3a and b). In elastase-instilled mice, 3-nitrotyrosine was detected mainly in the cytoplasm of cells bearing the morphological characteristics of alveolar type 2 cells, and colocalization experiments by laser confocal microscopy confirmed that the majority of 3-nitrotyrosine-positive cells $(83.4 \pm 6 \%, \quad P=0.03$ vs negative cells) also expressed proSFTPC, whereas only $21 \pm 5.6 \%$ of nitrotyrosine-positive cells expressed MAC-3 ( $P=0.03$ vs negative cells) (Figure 3c and d).

\section{iNOS Deletion Abolished Elatase-Induced Lung Protein Nitration but Did Not Prevent Emphysema}

We then aimed to determine whether eNOS or iNOS were required for the accumulation of nitrated proteins and the development of emphysema in the elastase-injured lung. Protein nitration and emphysema were not attenuated in $\mathrm{eNOS}^{-1-}$ mice compared with wild-type mice at day 7 after elastase instillation. In $\mathrm{iNOS}^{-1-}$ mice, the number of 3 -nitrotyrosine-positive cells was reduced by $62 \%$ compared with wild-type animals $(P=0.04)$; this effect was not associated with a reduction in the severity of emphysema in $\mathrm{iNOS}^{-1-}$ mice. Although the mean chord length of alveoli was markedly increased in elastase mice compared with the control group $(33.2 \mu \mathrm{m} \pm 4.6$ vs $21.5 \mu \mathrm{m} \pm 0.9 ; P=0.04)$, iNOS inactivation did not modify the elastase-induced increase in this parameter $(32.5 \mu \mathrm{m} \pm 5.9, P=0.99$ vs elastase) (Figure $4 a-c)$.

\section{Pharmacological Inhibition of iNOS Reproduced the Phenotype of iNOS ${ }^{-1-}$ Mice}

To control for compensatory mechanisms induced during development by germline deletion of the iNOS gene, wildtype mice were treated with $1400 \mathrm{~W}$, a specific iNOS inhibitor. At a dose of $20 \mathrm{mg} / \mathrm{kg} /$ day, $1400 \mathrm{~W}$ reduced by $72 \%$ the number of 3-nitrotyrosine-positive cells in the lung of elastase-instilled mice $(P=0.042$, Figure $4 \mathrm{~d})$. However, as was observed with iNOS ${ }^{-1-}$ mice, this major reduction in lung protein nitration did not translate into a reduction in elastase-induced emphysematous changes $(42.6 \mu \mathrm{m} \pm 3.5 v \mathrm{~s}$ $38.0 \mu \mathrm{m} \pm 2.9, P=0.45$ ) (Figure 4e). Similarly, $1400 \mathrm{~W}$ at a dose of $1 \mathrm{mg} / \mathrm{kg} /$ day did not reduce emphysema in elastaseinstilled C57B/6 mice (results not shown). To control bias relative to the choice of the $\mathrm{C} 57 \mathrm{~B} / 6$ strain for our experiments, Balb/c mice were used. As was observed in $\mathrm{C} 57 \mathrm{~B} / 6$ mice, 1400W had no protective effect against emphysema in Balb/c mice (results not shown).

\section{iNOS Inhibition Increased Markers of Oxidative Stress After Elastase Instillation}

As iNOS-derived peroxynitrite increases superoxide production in mitochondria, ${ }^{14}$ we determined whether iNOS inhibition would modulate the level of oxidative stress in the 

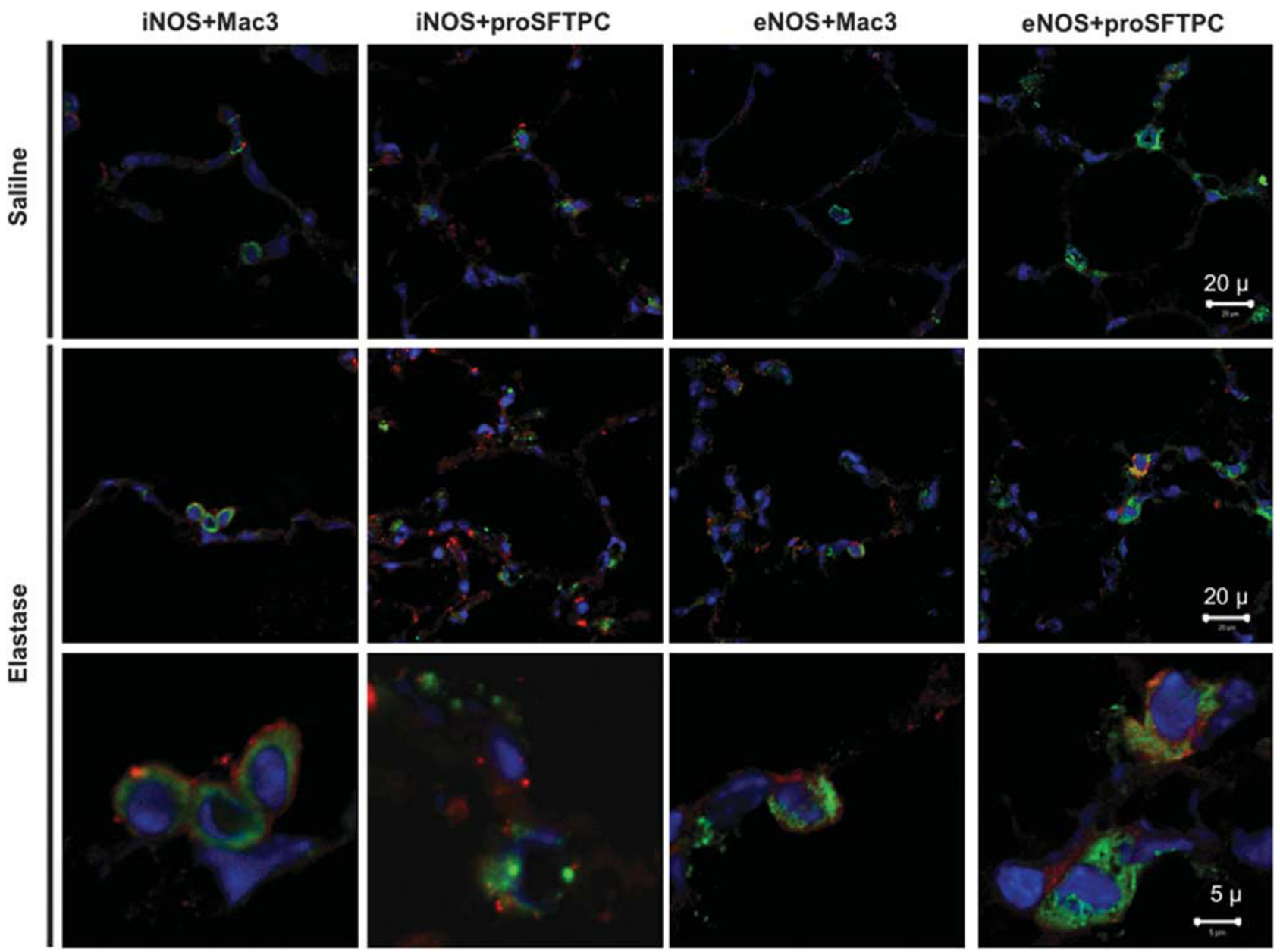

Figure 2 Immunolocalization of iNOS and eNOS in the lung at day 7 after elastase instillation. Colocalization of iNOS or eNOS expression (red signal) in the lung of saline and elastase-instilled mice with proSFTPC and Mac3 (alveolar type 2 cell marker and macrophage marker, respectively, green signal). Nuclei were stained with TO-PRO-3 (blue signal). First and second rows: $\times 63$ original magnification. Third row: $\times 252$ magnification of delimited area.

lung at day 7 after elastase instillation. Although elastase exposure alone did not increase protein carbonylation in the lung, a $141 \%$ increase in protein carbonylation was observed in $\mathrm{iNOS}^{-1-}$ compared with wild-type mice after elastase instillation $(P=0.032$, Figure 5a). Consistently with this result, $1400 \mathrm{~W}$ induced a $229 \%$ increase in protein carbonylation at day 7 after elastase instillation $(P=0.002$, Figure $5 b)$. By contrast, the induction at day 1 after elastase instillation of $\mathrm{HO} 1$ gene expression, another marker of oxidative stress, was not influenced by iNOS deletion (Figure 5c) or pharmacological inhibition (Figure 5d).

\section{iNOS Inhibition Did Not Reduce Inflammation, MMP Activity or Alveolar Cell Proliferation After Elastase Instillation}

Nitrotyrosine accumulation can be induced by neutrophil myeloperoxidase, ${ }^{15}$ and the inactivation of iNOS has been shown to reduce inflammation in models of lung injury. ${ }^{16,17}$ Thus, we tested the hypothesis that $1400 \mathrm{~W}$ may have reduced the accumulation of nitrotyrosine-positive material in the lung through a reduction in pulmonary inflammation. The influx in BALF of neutrophils (Figure 6a) or macrophages (Figure 6b) were not reduced in $\mathrm{iNOS}^{-1-}$ compared with wild-type mice at day 1 or day 7 after elastase instillation. Consistently with the lack of an anti-inflammatory effect of iNOS deletion, the pulmonary levels of CCL2, CXCL2, TNF $\alpha$, and IL6mRNAs were not different in elastase-instilled iNOS $^{-1-}$ and wild-type animals (Figure 6c-f). Similarly, pharmacological inhibition of iNOS neither reduced inflammatory cell counts, cytokine mRNAs (Supplementary Figure 1), or BALF CCL2 protein levels after elastase instillation (Supplementary Figure 2a), nor influenced the activity of MMP2 and MMP9, the main MMPs expressed, respectively, by macrophages and neutrophils, in BALF of elastase-instilled mice (Supplementary Figure 2b, c, and d). An $85 \%$ increase in alveolar cell proliferation was observed in the lung of elastase-instilled wild-type animals compared with saline-instilled mice. Treatment with $1400 \mathrm{~W}$ did not increase or decrease elastase-induced alveolar cell proliferation (Supplementary Figure 3). 

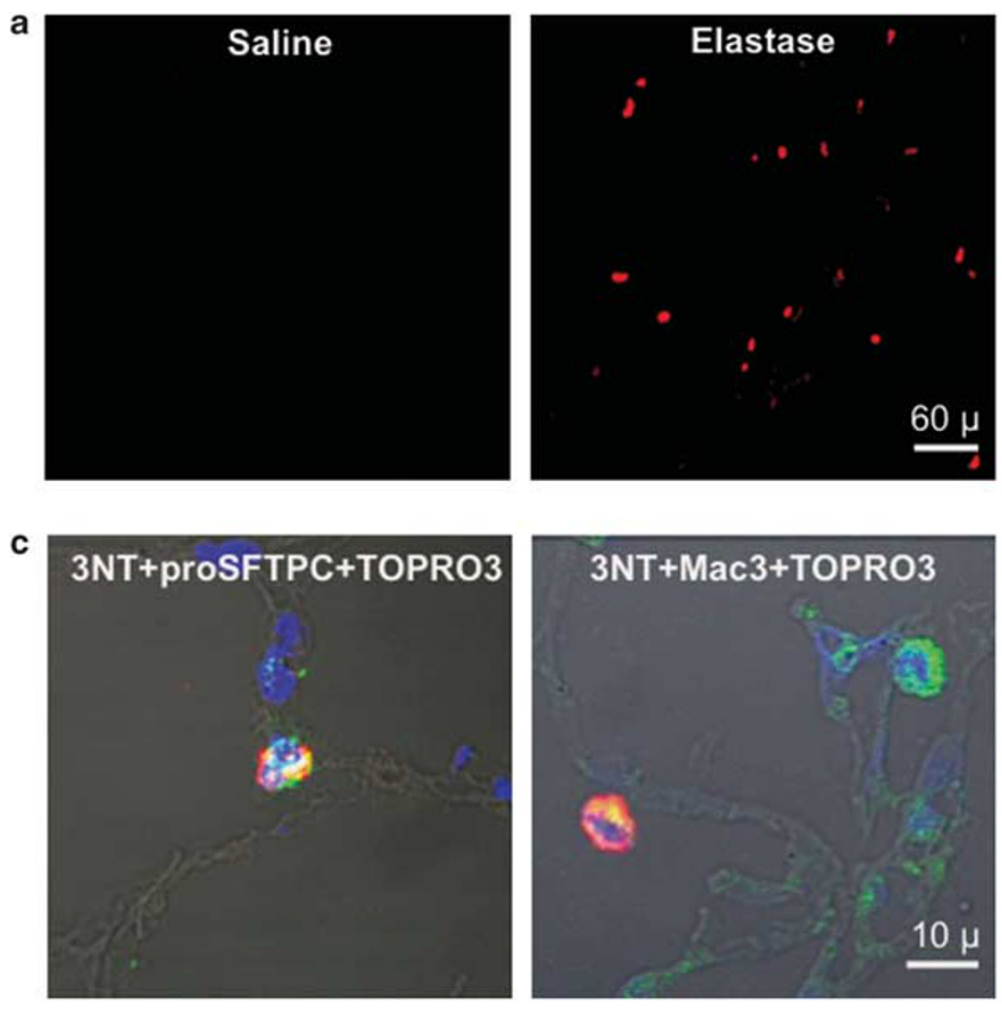
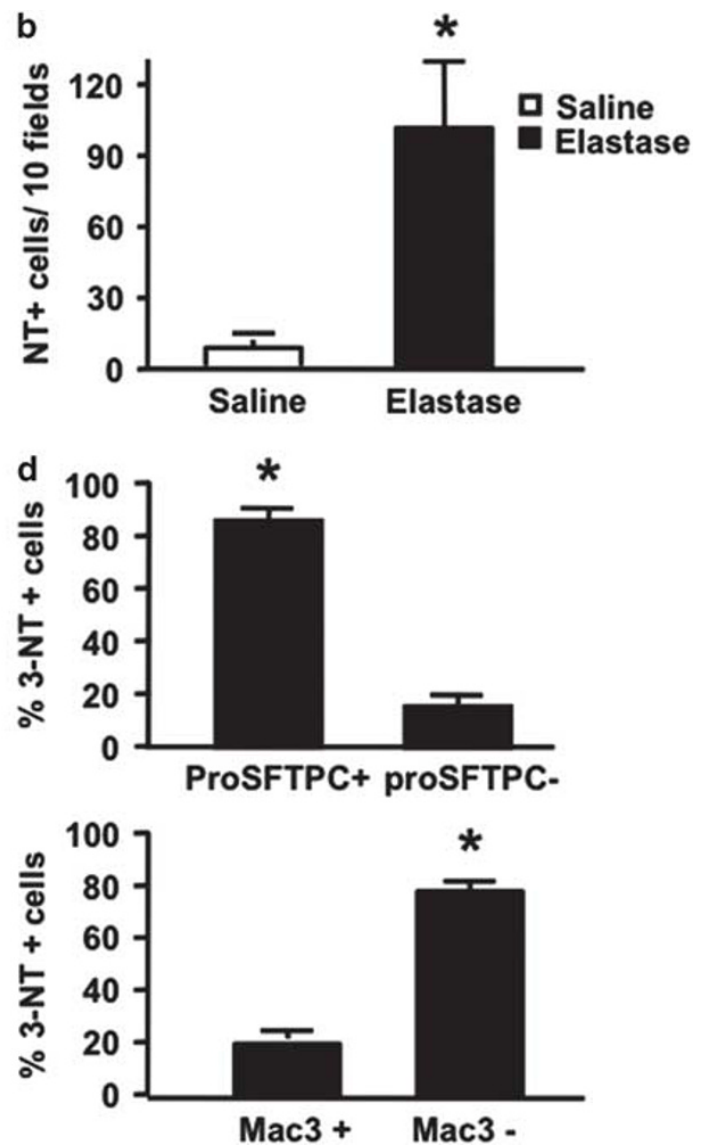

Figure 3 Elastase instillation induced the accumulation of nitrated proteins in alveolar type 2 cells. (a) Detection of 3-nitrotyrosine by fluorescence microscopy (red signal) in the lung of $\mathrm{C} 57 \mathrm{BL} / 6 \mathrm{~J}$ mice at day 7 after saline or elastase instillation. $\times 20$ original magnification. (b) Number of 3-nitrotyrosinepositive cells per 10 microscopic fields in saline (open bars) or elastase (closed bars)-instilled mice, $n=4$. ${ }^{\star} P<0.05$ vs saline. (c) Colocalization of 3-nitrotyrosine (red signal) with proSFTPC and Mac3 (both green signal) in the lung of elastase-instilled mice. Nuclei were stained with TO-PRO-3 (blue signal). $\times 63$ original magnification. (d) Percentage of 3-nitrotyrosine-positive cells expressing proSFTPC or Mac3 in the lung of elastase-instilled mice, $n=3$. Mean \pm s.e.

\section{DISCUSSION}

The main results of this study are (1) that iNOS and eNOS were diffusely induced in the mouse lung following a tracheal instillation of elastase, (2) that the induction of iNOS in the lung caused the accumulation of nitrated proteins in alveolar type 2 cells and to a lesser extent in macrophages, (3) that iNOS activity was not required for elastase-induced pulmonary inflammation, (4) that iNOS inactivation increased the level of oxidative stress in the elastase-instilled lung, and (5) that inactivation of eNOS or iNOS did not protect against elastase-induced emphysema. These findings provide evidence that iNOS-dependent protein nitration in alveolar type 2 cells accompanies but is not necessary for the development of elastase-induced pulmonary emphysema in mice.

Increases in lung iNOS expression and protein nitration were previously described in the lungs of patients with $\mathrm{COPD}^{7}$ as well as in experimental emphysema induced by inhibition of the VEGF receptor or surfactant protein D deficiency ${ }^{18,19}$; whether these phenomena contributed to airspace enlargement in these models was not reported, but could be suspected as iNOS contributes to inflammation and tissue remodeling in other models of lung injury such as endotoxin-induced pneumonitis, ${ }^{17}$ ventilator-induced lung injury, ${ }^{16}$ and silica-induced pulmonary fibrosis. ${ }^{20}$ In contrast with these observations, we observed that, whereas iNOS was strongly induced in the lung following elastase instillation, iNOS inhibition had no evident impact on pulmonary inflammation or emphysema development in this model. eNOS was not implicated neither in lung protein nitration nor in the development of emphysema following a tracheal instillation of elastase; deletion of eNOS was not deleterious either, although eNOS promotes compensatory alveologenesis after pneumonectomy. ${ }^{21}$ nNOS has been reported to be induced and/or to contribute to pulmonary inflammation in experimental models of lung disease, ${ }^{22,23}$ and it was surprising that this isoform was not induced in our model.

Elastase-induced emphysema is an artificial model that does not reproduce any and all features of smoke-induced COPD. Bronchial and small airway alterations, which are observed in the development of centrilobular emphysema in 
a

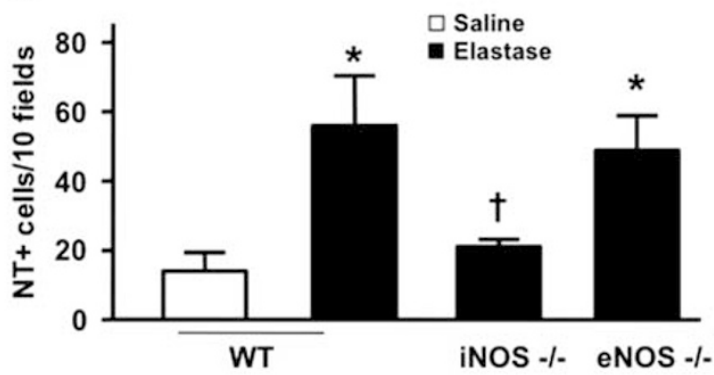

b

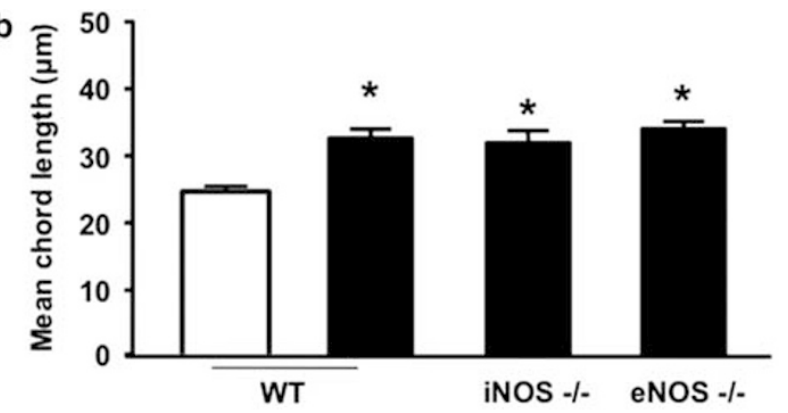

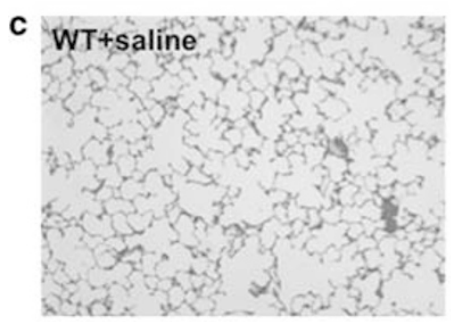

d

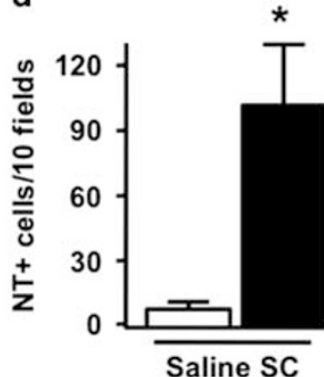

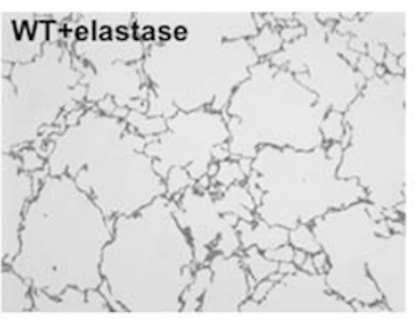

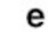 \\ e}

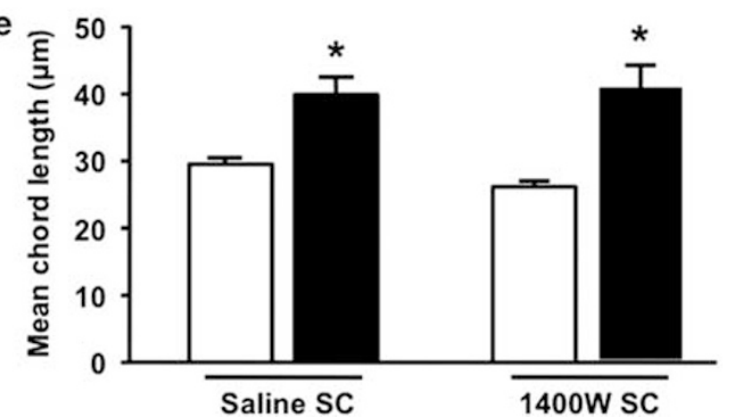

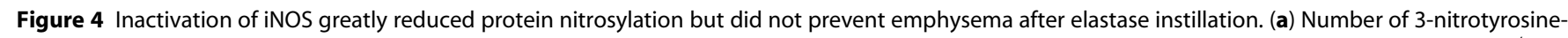

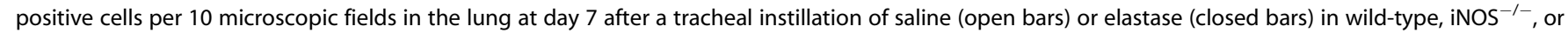
eNOS ${ }^{-1-}$ mice. $n=4$. ${ }^{\star} P<0.05$ vs wild-type/saline. ${ }^{\dagger} P<0.05$ vs wild-type/elastase. (b) Severity of emphysema assessed by the mean chord length of

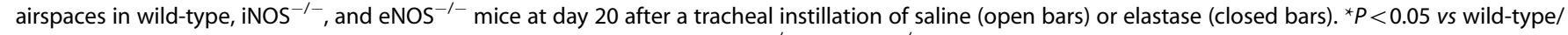

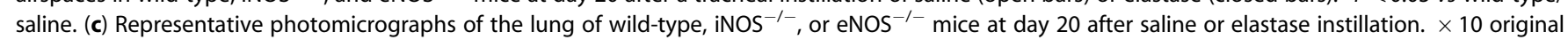

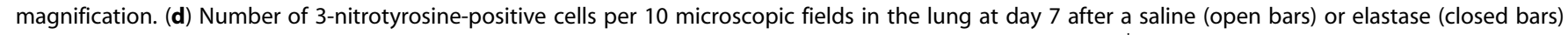

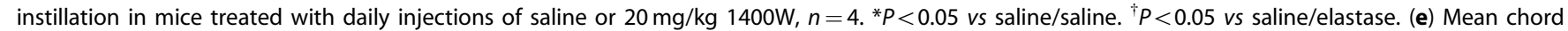
length of airspaces in the lung at day 20 after a tracheal instillation of saline or elastase in mice treated with subcutaneous saline or $20 \mathrm{mg} / \mathrm{kg} 1400 \mathrm{~W}$. ${ }^{\star} P<0.05$ vs saline/saline. $n=10$. Mean \pm s.e.

humans, ${ }^{24}$ are not reproduced by this model. However, elastase instillation in rodents reproduces key phenomena conducting to alveolar walls destruction and air space enlargement, which define lesions of emphysema. ${ }^{25}$ In our experiments, elastase instillation in mice reproduced the pattern of iNOS induction and protein nitration observed in the lung of patients with emphysema., ${ }^{7,26}$ Our observation that eNOS was also induced in the lung after elastase instillation was in line with the expression in COPD of constitutive NOS isoforms, as evidenced by the partial inhibition of alveolar NO production by inhaled aminoguanidine, a specific iNOS inhibitor, in these patients. ${ }^{10}$ Strengthening the relevancy of our model, the NOS expression profile induced by elastase instillation in our experiments was identical to that induced by cigarette smoke exposure in rats. ${ }^{27}$

Activity of all NOS isoforms can be regulated post-translationally, ${ }^{10,28}$ and it might be hypothesized that the lack of effect of eNOS or iNOS inactivation be related to already low levels of eNOS or iNOS activity. This question is of particular concern in the case of eNOS because we did not observe any morphological or biochemical effect of eNOS deletion. Our results, however, suggest that iNOS was indeed active in the elastase-injured lung, as iNOS inactivation was consistently associated with reduced nitration of lung proteins, a phenomenon directly linked to NO production. ${ }^{4}$ Neutrophil myeloperoxidase can induce protein nitration in the presence of nitrite and hydrogen peroxide. ${ }^{15}$ The fact that iNOS inactivation reduced elastase-induced protein nitration in the absence of a reduction in neutrophil counts pleads against the hypothesis that myeloperoxidase was a major contributor to protein nitration in our experiments.

The role of NO synthases in the distal lung remains unclear. The observation that protein carbonyls, a marker of oxidative stress, were increased in the lungs of $\mathrm{iNOS}^{-1-}$ and 

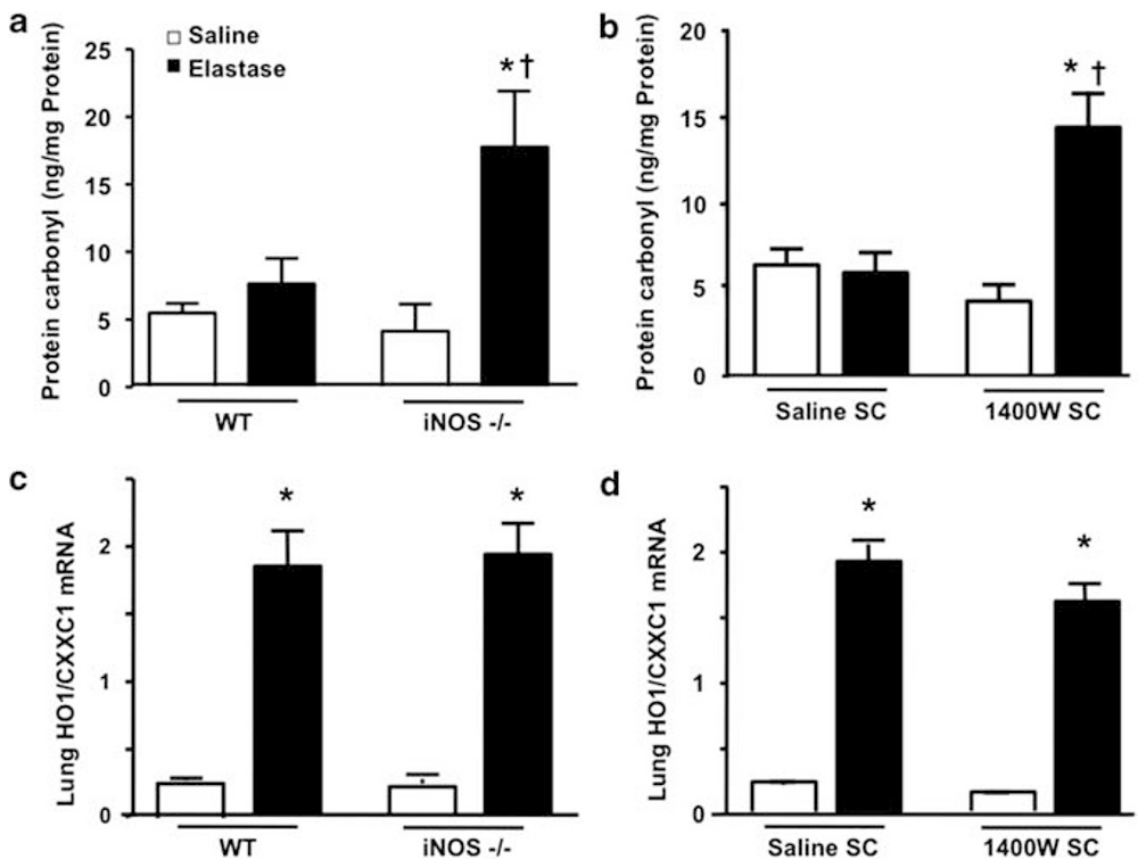

Figure 5 iNOS deletion or pharmacological inactivation increased oxidative stress in the lung of elastase-instilled mice. Lung protein carbonyl content quantified by ELISA at day 7 after saline (open bars) or elastase (closed bars) instillation in (a) wild-type and iNOS ${ }^{-1-}$ mice and (b) mice treated with daily injection of saline or $20 \mathrm{mg} / \mathrm{kg} 1400 \mathrm{~W}$. HO1 mRNA in lung homogenate at day after saline (open bars) or elastase (closed bars) in (c) wild-type and iNOS ${ }^{-1}$ mice, and (d) mice treated with daily injection of saline or $20 \mathrm{mg} / \mathrm{kg} 1400 \mathrm{~W}$. ${ }^{\star} P<0.05$ vs saline-instilled mice, ${ }^{\dagger} P<0.05$ vs saline/elastase or WT/elastase. $n=5$. Mean \pm s.e.
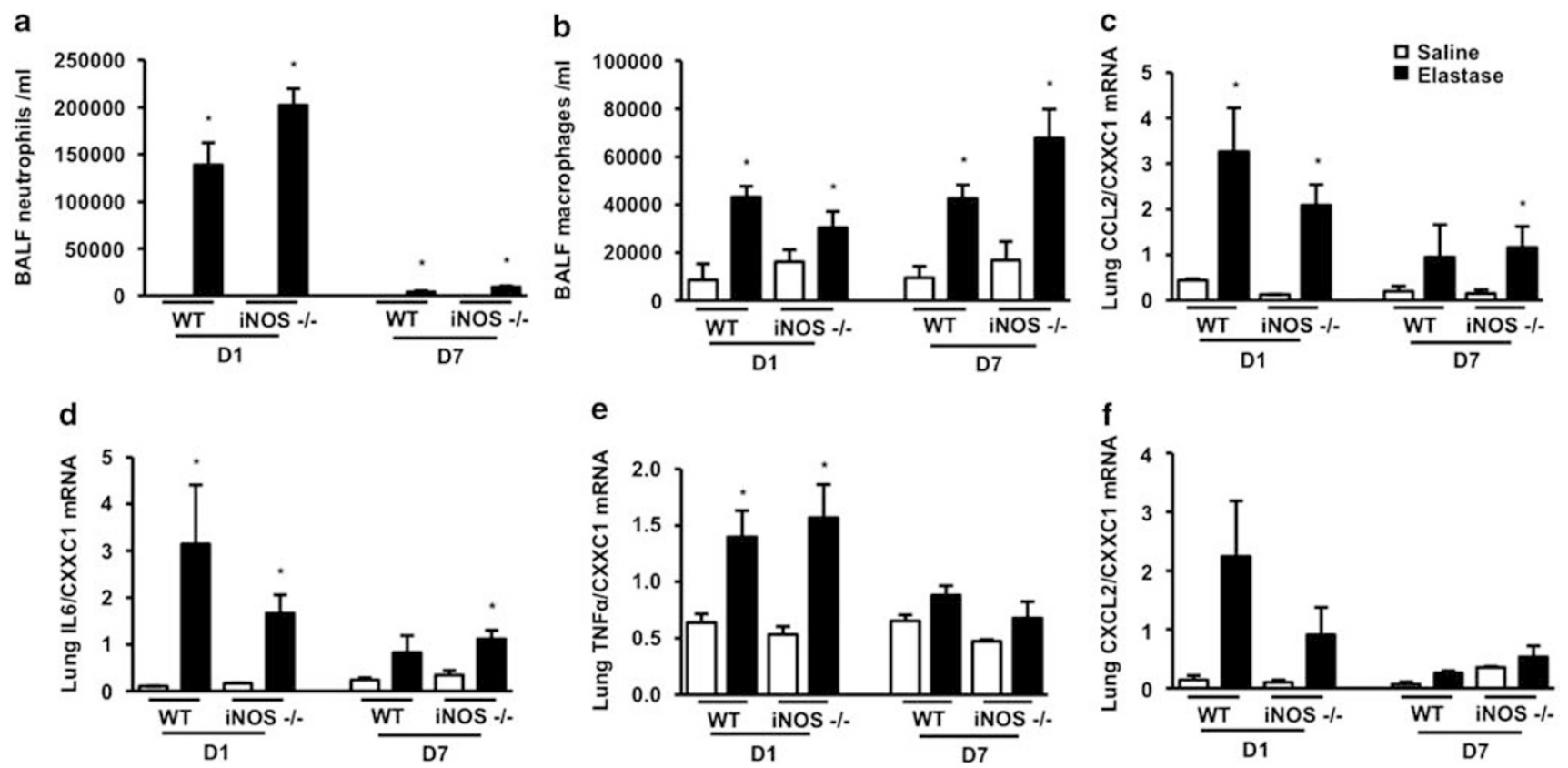

Figure 6 Inflammation was not reduced in iNOS ${ }^{-1-}$ mice at day 1 and day 7 after elastase instillation. (a) BALF neutrophil counts, (b) BALF macrophage counts, (c) lung CCL2 mRNA, (d) lung IL6 mRNA, (e) lung TNF $\alpha$ mRNA, and (f) lung CXCL2 mRNA, in wild-type and iNOS ${ }^{-1-}$ mice at day 1 and day 7 after a tracheal instillation of saline (empty bars) or elastase (closed bars). ${ }^{*} P<0.05$ vs saline-instilled mice. $n=5$. Mean \pm s.e.

$1400 \mathrm{~W}$-treated animals suggested that iNOS had an antioxidative role. Whether this effect was exerted through quenching of superoxide by $\mathrm{NO}$ or through a reduction in superoxide production was beyond the scope of this study, although the identical levels of $\mathrm{HO} 1$ gene expression in iNOS $^{-1-}$ and $1400 \mathrm{~W}$-treated animals compared with controls suggested that the production of oxygen reactive species was similar in all groups of animals. A detrimental increase in 
oxidative stress may have counterbalanced a putatively beneficial reduction in nitrosative stress in our model, resulting in a net null effect of iNOS deletion and inhibition. The preservation of alveolar cell proliferation in $\mathrm{iNOS}^{-1-}$ and $1400 \mathrm{~W}$-treated animals suggests that iNOS is not critical to alveolar repair.

In contrast with iNOS expression, which was diffuse in the alveolar wall, 3-nitrotyrosine staining mostly involved alveolar type 2 cells. Given that protein nitration reflects not only NO but also superoxide production, this finding indicates alveolar type 2 cells as the main cellular source of superoxide in alveolar walls in this model. Indeed, alveolar type 2 cells express NADPH oxidase and xanthine oxidase and are an important source of superoxide in the lung. ${ }^{29,30}$ Alternatively, the accumulation of nitrated proteins in alveolar type 2 cells may reflect a constitutive or elastase-induced vulnerability of these cells to nitrosative stress.

Interestingly, the absence of a cause and effect relationship between iNOS-dependent protein nitration and tissue destruction may be a general feature of models of elastaseinduced disease in elastin-rich organs, as similar results were reported in the elastase-induced abdominal aortic aneurysm model. iNOS and 3-nitrotyrosine expression are increased in human abdominal aortic aneurysms, ${ }^{31}$ as well as in the aorta of mice after elastase exposure. Similarly to our findings, elastase-induced aneurismal dilatation of the aorta is not reduced in $\mathrm{iNOS}^{-1-}$ mice, even though accumulation of 3 -nitrotyrosine is greatly reduced. ${ }^{32}$ Pulmonary emphysema and aortic aneurysms may be closely related diseases from a pathophysiological standpoint.

Strong data support a critical role of excess oxygen reactive species, or oxidative stress, in the course of experimental emphysema, ${ }^{1-3,33}$ which led to ask whether other reactive species would have a similar role in this disease. This study showed that iNOS, eNOS, and nitration of lung proteins were not required for the development of elastase-induced emphysema, suggesting that excess nitrogen reactive species may not be important players in the development of pulmonary emphysema.

Supplementary Information accompanies the paper on the Laboratory Investigation website (http://www.laboratoryinvestigation.org)

\section{ACKNOWLEDGEMENTS}

The authors thank Olivier Thibaudeau (Plate-Forme de Morphologie, IFR 02, Hôpital Bichat) for his assistance with preparing anatomic specimens, Xavier Decrouy (Palte-Forme Imagerie, IMRB, Université Paris Est) for his assistance with confocal microscopy, Indoumady Baskara (Service d'Immunologie Biologique, Inserm U955) for her technical assistance with RT-PCRs, and Christophe Delhomme (UMR 1019/UR454, Inra de Clermont Ferrand-Theix, France) for his assistance with breeding iNOS ${ }^{-/-}$mice needed for the revised version of this work. Laurent Boyer was the recipient of a grant by the Société de Pneumologie de Langue Française.

\section{DISCLOSURE/CONFLICT OF INTEREST}

The authors declare no conflict of interest.
1. reKinoshita $\mathrm{T}$, Hoshino $\mathrm{T}$, Imaoka $\mathrm{H}$, et al. Thioredoxin prevents the development and progression of elastase-induced emphysema. Biochem Biophys Res Commun 2007;354:712-719.

2. Rubio ML, Martin-Mosquero MC, Ortega $\mathrm{M}$, et al. Oral $\mathrm{N}$-acetylcysteine attenuates elastase-induced pulmonary emphysema in rats. Chest 2004;125:1500-1506.

3. Foronjy RF, Mirochnitchenko O, Propokenko $\mathrm{O}$, et al. Superoxide dismutase expression attenuates cigarette smoke- or elastasegenerated emphysema in mice. Am J Respir Crit Care Med 2006;173:623-631.

4. Pacher P, Beckman JS, Liaudet L. Nitric oxide and peroxynitrite in health and disease. Physiol Rev 2007;87:315-424.

5. Brindicci $C$, Ito $K$, Resta $O$, et al. Exhaled nitric oxide from lung periphery is increased in COPD. Eur Respir J 2005;26:52-59.

6. Ricciardolo FL, Caramori G, Ito $\mathrm{K}$, et al. Nitrosative stress in the bronchial mucosa of severe chronic obstructive pulmonary disease. J Allergy Clin Immunol 2005;116:1028-1035.

7. Maestrelli P, Paska C, Saetta M, et al. Decreased haem oxygenase- 1 and increased inducible nitric oxide synthase in the lung of severe COPD patients. Eur Respir J 2003;21:971-976.

8. Ichinose $M$, Sugiura $H$, Yamagata $S$, et al. Increase in reactive nitrogen species production in chronic obstructive pulmonary disease airways. Am J Respir Crit Care Med 2000;162(2 Part 1):701-706.

9. Yang SR, Chida AS, Bauter MR, et al. Cigarette smoke induces proinflammatory cytokine release by activation of NF-kappaB and posttranslational modifications of histone deacetylase in macrophages. Am J Physiol Lung Cell Mol Physiol 2006;291:L46-L57.

10. Brindicci $C$, Ito $K$, Torre $O$, et al. Effects of aminoguanidine, an inhibitor of inducible nitric oxide synthase, on nitric oxide production and its metabolites in healthy control subjects, healthy smokers, and COPD patients. Chest 2009;135:353-367.

11. Plantier L. Keratinocytes growth factor protects against elastaseinduced empysema in mice. Am J Physiol Lung Cell Mol Physiol 2007;293:1230-1239.

12. Garvey EP, Oplinger JA, Furfine ES, et al. $1400 \mathrm{~W}$ is a slow, tight binding, and highly selective inhibitor of inducible nitric-oxide synthase in vitro and in vivo. J Biol Chem 1997;272:4959-4963.

13. Pfaffl MW. A new mathematical model for relative quantification in real-time RT-PCR. Nucleic Acids Res 2001;29:e45.

14. Carreras MC, Franco MC, Peralta JG, et al. Nitric oxide, complex I, and the modulation of mitochondrial reactive species in biology and disease. Mol Aspects Med 2004;25:125-139.

15. Burner U, Furtmuller PG, Kettle AJ, et al. Mechanism of reaction of myeloperoxidase with nitrite. J Biol Chem 2000;275:20597-20601.

16. Peng $X$, Abdulnour RE, Sammani $S$, et al. Inducible nitric oxide synthase contributes to ventilator-induced lung injury. Am J Respir Crit Care Med 2005;172:470-479.

17. Okamoto T, Gohil K, Finkelstein El, et al. Multiple contributing roles for NOS2 in LPS-induced acute airway inflammation in mice. Am J Physiol Lung Cell Mol Physiol 2004;286:L198-L209.

18. Petrache I, Fijalkowska I, Zhen L, et al. A novel antiapoptotic role for alpha1-antitrypsin in the prevention of pulmonary emphysema. Am J Respir Crit Care Med 2006;173:1222-1228.

19. Atochina-Vasserman EN, Beers MF, Kadire $\mathrm{H}$, et al. Selective inhibition of inducible NO synthase activity in vivo reverses inflammatory abnormalities in surfactant protein D-deficient mice. J Immunol 2007;179:8090-8097.

20. Zeidler P, Hubbs A, Battelli $L$, et al. Role of inducible nitric oxide synthase-derived nitric oxide in silica-induced pulmonary inflammation and fibrosis. J Toxicol Environ Health A 2004;67:1001-1026.

21. Leuwerke SM, Kaza AK, Tribble CG, et al. Inhibition of compensatory lung growth in endothelial nitric oxide synthase-deficient mice. Am J Physiol Lung Cell Mol Physiol 2002;282:L1272-L1278.

22. De Sanctis GT, MacLean JA, Hamada K, et al. Contribution of nitric oxide synthases 1,2, and 3 to airway hyperresponsiveness and inflammation in a murine model of asthma. J Exp Med 1999;189:1621-1630.

23. Demchenko IT, Atochin DN, Gutsaeva DR, et al. Contributions of nitric oxide synthase isoforms to pulmonary oxygen toxicity, local vs. mediated effects. Am J Physiol Lung Cell Mol Physiol 2008;294:L984-L990.

24. Hogg JC. Pathophysiology of airflow limitation in chronic obstructive pulmonary disease. Lancet 2004;364:709-721.

25. Wright $\mathrm{J}$, Cosio M, Churg A. Animal models of chronic obstructive pulmonary disease. Am J Physiol Lung Cell Mol Physiol 2008;295:L1-15. 
26. Brindicci $C$, Kharitonov $S A$, Ito $M$, et al. Nitric oxide synthase isoenzyme expression and activity in peripheral lung tissue of patients with chronic obstructive pulmonary disease. Am J Respir Crit Care Med; 181:21-30.

27. Wright JL, Dai J, Zay K, et al. Effects of cigarette smoke on nitric oxide synthase expression in the rat lung. Lab Invest 1999;79:975-983.

28. Lanone $S$, Manivet $P$, Callebert J, et al. Inducible nitric oxide synthase (NOS2) expressed in septic patients is nitrated on selected tyrosine residues: implications for enzymic activity. Biochem J 2002;366 (Part 2):399-404.

29. Saito S, Ogawa J, Minamiya Y. Pulmonary reexpansion causes xanthine oxidase-induced apoptosis in rat lung. Am J Physiol Lung Cell Mol Physiol 2005;289:L400-L406.
30. Chapman KE, Sinclair SE, Zhuang D, et al. Cyclic mechanical strain increases reactive oxygen species production in pulmonary epithelial cells. Am J Physiol Lung Cell Mol Physiol 2005;289: L834-L841.

31. Zhang J, Schmidt J, Ryschich $\mathrm{E}$, et al. Inducible nitric oxide synthase is present in human abdominal aortic aneurysm and promotes oxidative vascular injury. J Vasc Surg 2003;38:360-367.

32. Lee JK, Borhani $\mathrm{M}$, Ennis $\mathrm{TL}$, et al. Experimental abdominal aortic aneurysms in mice lacking expression of inducible nitric oxide synthase. Arterioscler Thromb Vasc Biol 2001;21:1393-1401.

33. Rangasamy T, Cho CY, Thimmulappa RK, et al. Genetic ablation of Nrf2 enhances susceptibility to cigarette smoke-induced emphysema in mice. J Clin Invest 2004;114:1248-1259. 